\title{
The Design and Application of Public Security Risk Register in Beijing City Community
}

\author{
Hui Lyu ${ }^{1,2}$, Xin Bai ${ }^{1,2}$ \\ 1 Beijing Radiation Center, Beijing, 100875 \\ 2Beijing Research Center of Urban System Engineering, Beijing, 100035
}

\section{北京城市社区公共安全风险登记册设计及应用}

\author{
吕慧 ${ }^{1,2}$, 白金金 ${ }^{1,2}$ \\ 1 北京市辐射中心，北京， 1000875 \\ 2 北京城市系统工程研究中心城市安全部, 北京, 100035
}

\begin{abstract}
Community is the cell of city. Community risk is an important breeding ground and management object for the whole city and social safety. The community risk register provides a framework and system to check risk information. In this paper, based on the risk register concepts, processes, research progress at home and abroad, a set of risk register specification program which was suitable for China was show. It included a risk register format, content, assessment processes and proposal. Finally, a urban community risk assessment result was got in Beijing by using the risk register program, and some suggestions were put forward from safety management, safety environment, Safety facilities, safety awareness and skills.
\end{abstract}

Keywords: urban communities; public safety; risk communities; risk register

\section{摘要}

社区是城市的细胞, 社区风险是整个城市、社 会风险的重要滋生地和重要管理对象。社区风 险登记册为核对社区风险信息提供了一个框 架和体系。本文在对风险登记册的相关概念、 流程以及国内外研究进展进行综述的基础上, 提出一套适用于我国城市社区公共安全领域
的风险登记册规范方案, 方案包括风险登记册 格式、内容、评估流程以及给社区风险登记工 作的管理建议。最后, 本文将此套风险登记册 应用于北京市某城市社区, 得到了该社区的风 险评估结果, 并从安全管理、安全环境、安全 设施、安全意识与技能四个方面提出了对策建 议。

关键词：城市社区; 公共安全; 社区风险; 风险登记

1. 引言

1986 年, 德国社会学家乌尔里希・克出 版了《风险社会》一书, 他将现代社会解释为 风险社会。城市公共安全作为一个系统, 它的 风险由于人群的聚集而被放大, 由于系统的脆 弱性而已受破坏, 由于系统的社会敏感性而被 激化及猝变 ${ }^{[1]}$ 。

基层单位风险是整个城市、社会风险的重 要滋生地和重要管理对象 ${ }^{[2]}$ 。然而目前风险管 理还是至上而下的任务推派较多, 缺少至下而 上的风险发现和及时处理的机制。

社区风险登记为核对风险信息提供了一 个框架和体系, 有助于风险分析和消减, 是基 层风险管理的一种科学有效的方法, 有助于风 险的及时发现、及时处理和及时解决, 能够让 风险尽量处于可控状态。 


\section{2. 城市社区风险及应对手段}

2.1 城市社区风险源

风险源（risk source）即引起或产生风险 的因素。对城市经济和社会发展带来风险的危 险源主要有城市工业危险源、城市公共场所、 城市公共基础设施、城市自然灾害、城市生态 环境、恐怖袭击与破坏、城市道路交通等。

其中, 公共设施和公共场所所带来的风险尤其 值得关注。公共设施是公共安全的主要风险源 之一。城市对水、电、气、油、信息、交通等 资源的依赖性高, 因而也使遍布城市地上地下 纵横交错的自来水、煤气、天然气管网和电信、 电力、网络管线系统显得特别复杂。公共场所 安全问题成为社会关注的重点城市的基本特 点就是人口密度高, 人员流动频率高, 这些特 点在公共场所尤为突出, 如商场、超市、车站 码头、城市广场、娱乐服务场所、宾馆、公园、 旅游景区等场所, 都不同程度存在各类安全隐 患, 如: 安全设施陈旧、通道不畅、照明不足、 安全标识不清、安全设施检测合格证过期等 等。近年来事故频发, 更是危害严重。

\section{2 社区风险应对}

加强社区灾害风险管理是当前减灾的主 要趋势之一。目前我国社区风险管理还存在总 体发展不平衡、社会化参与程度不高、综合减 灾系统机制不完善、防灾规划和应急预案针对 性不强、防灾减灾宣传力度和减灾资源整合力 度不够等问题 ${ }^{[2]}$ 。

风险登记是各种威胁组织取得既定目的 和目标的风险的记录。它是一个动态的文件, 随着组织风险评估过程和结果的变化而变化。 风险登记使得风险得以量化和区别轻重程度, 为核对风险信息提供了一个框架和体系, 有助 于风险分析和消减。

社区风险登记是应急规划过程的第一步, 以确保规划和其它工作的开展与风险相适应 [3]。

\section{3. 国内外风险登记的经验}

\section{1 国外风险登记的经验}

作为国际公认的世界城市, 伦敦、纽约、 东京 ${ }^{[4]}$ 都是以风险管理为主要手段, 结合各自 的国情市情, 分别形成了以全面风险普查登
记、自然灾害风险和城市关键基础设施风险评 估、巨灾风险评估为基本特点的城市安全风险 管理体系, 风险管理工作已逐步进入制度化、 规范化、精细化和科学化的轨道。

伦敦按照全国统一的格式进行风险普查 登记, 列出当地面临的各级各类风险, 形成本 地区的风险登记册 ${ }^{[5]}$ 。

纽约的城市安全风险评估工作由纽约市 减灾规划委员会负责, 制定减缓或消除灾害影 响的各种现有或潜在综合性减灾措施登记单。

东京的风险登记主要是围绕地震灾害来 展开的, 称之为 “城市综合危险度评估”。

可以看到, 这几个具有代表性的世界城市 在风险管理上, 都是以基层工作为抓手, 从基 本单元开始入手编制相应的风险登记册, 并统 一了格式。

\section{2 我国风险登记工作的进展}

目前我国对社区风险登记的研究尚处在 学习国外先进经验, 对我国社区风险登记工作 进行初步梳理的初级阶段, 钟开斌 ${ }^{[4]}$ 对伦敦以 全面风险登记为基本特点的城市风险管理体 系做了全面的阐述, 并从关口前移、强化法制、 统一规范、跨域合作、公开透明等五个方面总 结了伦敦城市风险管理工作的主要经验。

朱伟 ${ }^{[6]}$ 建议北京市应急管理工作应从风 险登记流程及标准建立、风险登记结果量化分 析及控制方法、风险登记动态监控技术三方面 出发用于支持北京市公共安全形势分析和服 务公共安全风险管理决策。

付建华 ${ }^{[7]}$ 以管道生命周期各阶段及相关 生产作业活动、场所（区域）的划分为基础, 提出了建立风险登记册以实施油气管道日常 生产过程中的风险动态管理和监控。

周永根 ${ }^{[3]}$ 等梳理了我国城市基层单位风 险等级标准体系类目与标准, 提出了城市基层 单位风险等级标准体系框架, 建议从机构建 设、风险管理标准、制度机制、队伍建设、经 费投入和宣传教育等方面加强城市基层单位 风险管理。

\section{4. 城市社区风险登记册方案设计}

4.1 城市社区风险登记册的内容

基于国外风险登记经验和北京市城市社 


\section{Risk Analysis and Crisis Response in Big Data Era (RAC-16)}

区风险特点, 建立一套符合北京市城市社区特 点的风险登记册。

城市社区风险登记表将由社区、街道负责 风险管理的部门、风险评估专家共同完成并确 认, 风险登记册内容包括对本社区可能产生潜 在影响的各种自然灾害、公共卫生、事故灾难、 社会治安等四大类风险信息。

\section{2 社区风险登记册的格式}

以北京市城市社区的风险特点为研究对 象, 归纳出城市社区面临的各级各类风险, 初 步形成社区风险登记册。

风险登记表的主要内容包括: 风险代码、 风险大类、风险小类、后果描述、发生可能性、 后果严重度、风险评级、控制措施、是否危及 相邻地方、是否有预警措施等十项内容。

各社区通过对各级各类风险进行系统、完 整的登记, 并汇总给街道。街道应列出本地区 各级各类风险具体情况, 并通过风险矩阵确定 风险优先等级。

\section{3 社区风险登记册的评估}

社区在进行风险识别后, 根据 “风险=可 能性*影响” 的标准, 评估该风险在近一年内 的可能性以及可能造成的后果。

风险发生的可能性和后果严重度各分为 “低、中、高”三个等级, 最终的风险评级的 结果由以上二者相乘, 将风险由低到高划分为 低风险、中风险和高风险三个等级。在此基础 上, 可形成风险矩阵, 进行不同类别风险的排 序。通过风险识别和评估, 将产生《社区风险 登记册》, 为社区、街道有效监督和处置风险、 编制应急预案提供数据支撑。

根据健康、社会、经济和环境四个方面的 影响, 即综合考虑人员伤亡、财产损失、需要 转移安置的人员、对当地基础设施和社区服务 的影响、对经济和环境的影响等指标, 风险造 成的影响从低到高也分为 3 个等级。

\section{4 社区风险登记工作的管理建议}

街道应建立专门的风险登记管理机构和队 伍, 制定风险登记的更新和发布制度。社区风 险登记管理队伍可由社区灾害信息员、志愿 者、居民等多方组成。通过充分发挥灾害信息
员的作用，可把风险信息传达给居民，并同时 上报、登记入册; 居民通过积极参与风险登记 工作, 一方面可逐步提升安全意识, 另一方面 居民将发现的风险情况及时通报灾害信息员, 为社区风险登记工作提供了信息渠道。

充分发挥行业专家力量, 对社区风险登记 工作进行培训、引导和把关。从事社区风险研 究领域的专家、学者可为社区风险登记工作提 供咨询和指导, 通过培训帮助社区相关工作人 员了解风险登记工作的基础知识, 通过现场风 险识别引导编制本社区的风险登记册, 并为最 后的风险登记册质量和结果把关。此外, 各社 区应在风险登记册编制完成后, 根据风险态势 的变化、专家意见, 定期组织讨论会, 修订一 些新的情况, 对风险进行更新, 使得社区风险 登记册可以及时反映社区现状。

加大对公共安全风险登记的宣传工作, 提 高辖区居民的安全意识。通过新闻媒体、网络 平台、宣传资料等多种形式, 宣传风险管理标 准化知识和技术, 将辖区风险评估和登记的结 果公布于街道网站、报纸、微博、微信公众号、 宣传栏等公开媒体或渠道上, 并接受社会各 界、居民的监督和反馈。

\section{5. 城市社区公共安全风险登记册的应用}

5.1 社区风险登记结果

为验证城市社区公共安全风险登记册的 科学性与实用性, 对北京市西城区某社区进行 试点应用, 得到社区公共安全风险登记表如图 1 所示。

统计结果显示, 本社区存在高风险 10 项, 中风险 12 项, 低风险 8 项。高风险事故主要 存在火灾、刑事案件和踩踏事故, 中风险事故 主要存在于内涝、盗窃、抢劫、诈骗、扰乱公 共秩序等方面。

\section{2 对策建议}

风险登记册的编制作为社区风险管理全 过程的第一环节, 这并不是最终的目的, 而是 社区防灾减灾工作的重要手段。

风险登记册作为风险沟通 ${ }^{[8]}$ 的一种方法 和手段, 有助于街道和社区居民对社区本身的 脆弱性及其各类风险隐患了解得更加全面, 这 是社区能对风险做出有效应对的重要基础。在 


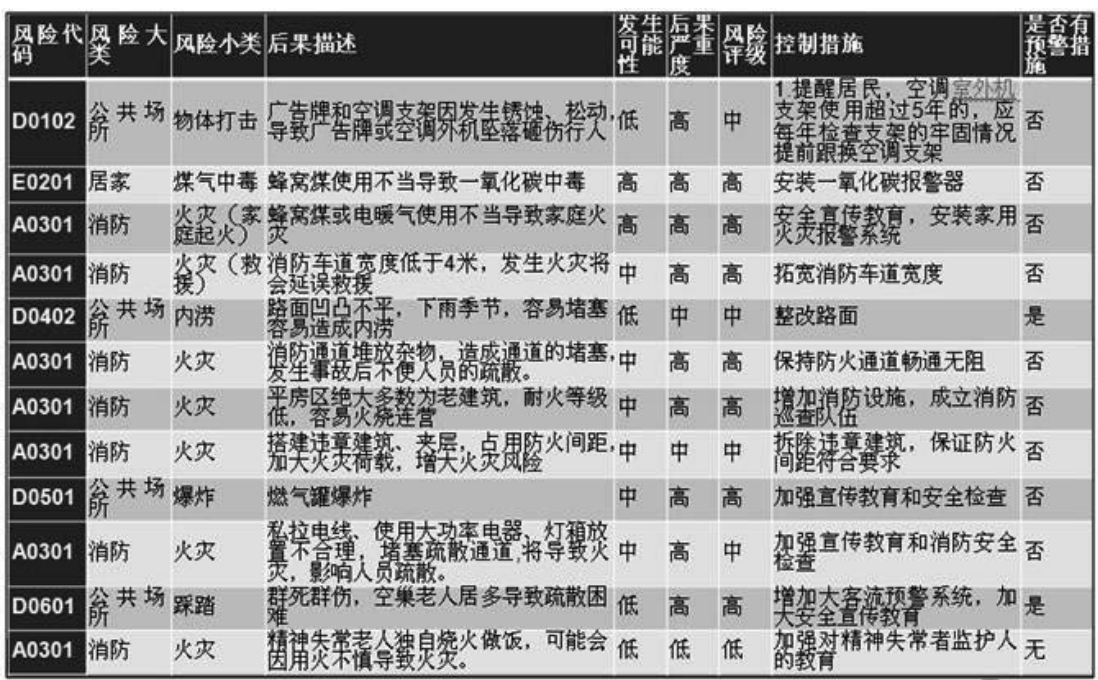

图 1. 一个社区的公共安全风险登记表

此基础上, 还需细化对于风险登记册如何有效 运用的理解和认识, 制定向其他社区居民进行 宣传教育的计划和实践。

以下从安全管理、安全环境、安全设施、 安全意识与技能几方面对社区风险管理工作 提出一些建议。

\subsection{1 安全管理}

(1) 通过巡查、举报等方式, 保证防火通道 畅通无阻;

（2）定期进行电梯维护保养检查;

（3）规范地下室安全管理，预防地下空间火 灾事故;

（4）排查六小场所私拉乱接电线情况。

\section{2 .2 安全环境}

(1) 合理规划小区停车位, 解决乱停车现象;

(2) 拆除违章建筑，保证防火间距符合要求;

（3）整改凹凸不平的路面，避免内涝;

（4）改造消防车道，使其宽度符合要求;

（5）对老旧线路进行改造, 避免电气火灾发 生。

\section{2 .3 安全设施}

（1）为老旧平房区增加消防灭火设施，试行 “一院一灭火器”计划;

（2）安装防盗锁等防盗设施;
（3）增加大客流预警系统，避免踩踏事故;

（4）对使用蜂窝煤的住户安装一氧化碳报警 器。

\subsection{4 安全意识与技能}

（1）提醒居民空调室外机支架使用超过 5 年 的，应每年检查支架的牢固情况并提前跟换;

(2) 对诈骗、盗窃等手段和预防措施进行宣 传, 提高居民安全意识;

（3）针对辖区有精神失常老人独自烧火做饭 现象, 加强对精神失常者监护人以及周围居民 的安全教育工作;

(4) 针对私拉电线、使用大功率电器、堵塞 疏散通道等居民应加强消防安全知识的宣传 教育工作。

\section{参考文献}

[1]向良云. 非常规群体性突发事件演化机理 研究. 上海: 上海交通大学, 2012 .

[2]陈容, 崔鹏.社区灾害风险管理现状与展望, 灾害学，2013 (1): 133-137.

[3]周永根，秦挺金金，陈锐.城市基层单位风险 等级标准体系研究. 灾害学 2015 (7): 140:149.

[4]钟开斌.伦敦城市风险管理的主要做法与经 验. 国家行政学院学报, 2011（05): 113-117.

[5]LONDON FIRE BRIGADE, London Community Risk Register. 2010(02) 
Risk Analysis and Crisis Response in Big Data Era (RAC-16)

[6]朱伟,首都公共安全突发事件风险登记工作 探讨, 2012 学术前沿论从一一科学发展: 深化改革与改善民生（下）中国会 议:556-560.

[7]付建华, 王毅辉, 李又绿等.油气管道全生 命周期安全风险管理.天然气工业，2013 (12): 138-143.
[8]T.H. Liu, H.B. Zhang, X.W. Li, H.R. Li. The effects of the social context on predecisional processes of protective action in Beijing communities. Journal of Risk Analysis and Crisis Response, 2016, 6(1): 21-30 